the foundations of this easy system of medical confidentiality. Firstly, both the government and the courts of law have failed to recognise the principles on which the system is based. The Law Reform Committee and the Criminal Law Revision Committee have pronounced that there is little if any reason to treat confidential medical information any differently from that passing between a minister of religion and his flock, and medical confidences are given no privilege whatsoever in English courts of law. It takes only a short trip across the straits of Dover to reach a country where medical information enjoys absolute privilege in the courts. Worse still, the House of Lords has recently upheld the right of a lay councillor in local government to see confidential medical information in social service committee records even though she had nothing to do with the case and was not even a member of the committee. ${ }^{1}$ Furthermore, last year the government itself attempted to introduce into the Police and Criminal Evidence Bill the opportunity for the police to obtain easy access to medical records on the flimsiest of grounds-an attempt which would have been successful had not doctors and the public reacted with outrage.

The second development has been the rapid growth in the number of agencies which are now concerned with the diagnosis, treatment, and management of patients. These agencies need access to appropriate information if they are to handle their cases efficiently and safely. They are, of course, committed to keeping confidential any information entrusted to them by doctors. But what happens when the information is processed into data which are then stored mechanically to facilitate access? The need to place controls on access to data on computers was emphasised by both the Younger Committee on Privacy ${ }^{2}$ and the Lindop Committee on Data Processing. ${ }^{3}$ The government decided to act, however, only when the commercial disadvantages became apparent of Britain's failing to implement the recommendations of the Council of Europe and the Organisation for Economic Cooperation and Development on the subject.

As soon as the Data Protection Bill appeared its safeguards against unjustified disclosure of medical information were seen to be seriously defective, and an interprofessional working group was set up under the chairmanship of Sir Douglas Black to secure appropriate amendments. At first the government was remarkably unhelpful, pointing out (with justification) that the bill does not compel anyone to disclose anything. The bill had already passed through the Lords and was well on its way through the committee stage before the group's first success was announced. It had persuaded the Minister of Health to take powers under the National Health Service Act to require all data users in the NHS to observe a code of guidance covering the handling and disclosure of health information.

The key issue in the code is the requirement that the doctor who is responsible for the patient should be consulted before disclosure. But what of data which has got on to computers outside the health service or which is based on information collected outside the health service? The group went back to the Home Secretary in March to point out that the position would not be secure until he took powers under the bill to require all data users to comply with a code of guidance in respect of health information, and the Home Secretary promised to do what he could "within the context of the bill." As the Commons committee has already dealt with the relevant clause in the bill, it will not be until the report stage-the last possible opportunity-that the government may act. If the Home Secretary has been persuaded to do what the group wants, patients will have good reason to thank Sir Douglas
Black and the members of his group for the long and hard battle which they have fought.

The lesson of this bill is that at a time when large amounts of information can be speedily transferred around the world doctors must be vigilant if the traditional confidentiality of medical records is to be preserved.

Secretary,

J D J HAVARD

British Medical Association,

London WC1H 9JP

\footnotetext{
City of Birmingham District Council v " $O$ " and another. (1983) 3 All ER 497, p 503.

${ }^{2}$ Home Office. Report of the committee on privacy. London: HMSO, 1972. (Cmnd 5012.) (Younger report.)

${ }^{3}$ Home Office. Report of the committee on data protection. London: HMSO, 1978. (Cmnd 7341.) (Lindop report.)
}

\section{The sweet road to gall stones}

Much has been discovered in the past 15-20 years about the mechanisms by which cholesterol gall stones form but less about their cause. We know from research on coronary heart disease that the way to identify risk factors is to do large scale epidemiological surveys-and especially prospective, longitudinal studies like the Framingham study. Such studies are only just beginning with gall stone disease. Case-control studies have been done but with inadequate numbers and with suboptimal techniques.

The new case-control study by Scragg and his colleagues in Adelaide is exemplary, with a large number of cases (267), the use of randomly' selected but carefully matched controls from the community, and detailed statistical analysis. The authors plan a series of reports on the predictive power of nearly all the postulated risk factors: female sex hormones, multiparity, obesity, hypertriglyceridaemia, low plasma concentrations of high density lipoprotein cholesterol, and impaired carbohydrate metabolism. The first report ( $p$ 1113) deals with body weight, alcohol intake, and, especially, diet.

On body weight one finding was surprising: obesity was a risk factor only in women aged under 50 . In men there was not even a hint that those with gall stones were heavier than controls. This is odd, since obese men certainly have bile which is supersaturated with cholesterol. ${ }^{12}$ Admittedly, in the Adelaide study body fatness was assessed indirectly through Quetelet's index (weight divided by height squared), and this index may be the same in a person who is small boned and fat and one who is lean but big boned or heavily muscled. Direct measurements of body fatness must be made in a case-control study before obesity can be proved not to be a risk factor in men. The finding that older women with gall stones are not fatter than average has been foreshadowed in earlier studies. Those overweight women in whom obesity does lead to gall stones are perhaps destined to develop their stones early in their lives. Obesity does not make everyone a gall stone former.

The contribution of diet has been examined in the past by case-control studies and by experiments. Case-control studies have given confusing results, with excessive energy intake implicated in some and exonerated in others. Scragg et al suggest two explanations. Firstly, previous studies were too small and had methodological deficiencies. Secondly, their study showed high energy intake to be a risk factor only at younger ages. Indeed, at high energy intakes there was a 
linear decline in relative risk with increasing age. This is a provocative new finding which will force other researchers to look more carefully at their data for an effect of aging. Scragg's explanation seems plausible-that those susceptible to high energy intakes and obesity are selected out at an early age. It fits with recent evidence that oral contraceptives merely accelerate the development of gall stones without increasing their overall incidence. ${ }^{3}$ Alternatively, high energy intake and obesity might be lithogenic only in the presence of high concentrations of female sex hormones.

The individual dietary items that have most often been suspected of favouring gall stone formation are sugar and fat (if only because they tend to inflate energy intake) and cholesterol. The evidence has been scanty. Now, however, the Adelaide study provides impressive evidence to incriminate refined (in the sense of fibre depleted) sugar. Total intake of sugar, which includes natural sugar in fruit and vegetables but consists mainly of refined sugar in most people's diet, was higher in younger patients of both sexes. Sugar in drinks and sweets, which is almost all refined sucrose, was higher at all ages.

These data provide strong support for the refined carbohydrate hypothesis. ${ }^{4}$ Scragg et al found sugar to be a risk factor independent of obesity. One possibility is that sugar may act by stimulating secretion of insulin since insulin stimulates cholesterol synthesis in vitro, ${ }^{5}$ and some people have raised plasma insulin concentrations when they are taking a high sugar intake. ${ }^{6}$ If dietary sugar does cause gall stones it must be either a delayed effect or one not mediated by the cholesterol saturation of bile-since a recent study showed that the lipid composition of bile was the same after six weeks of taking low and high sugar diets. ${ }^{7}$

The idea that a high cholesterol intake favours an excess of cholesterol in the bile and so gall stones may seem plausible, but again the evidence is scanty. The Adelaide study resembles other case-control studies and most ${ }^{8-10}$ but not all ${ }^{11}$ experimental studies in finding no evidence to blame gall stones on high dietary cholesterol. This is not really surprising since dietary cholesterol is probably a minor source of biliary cholesterol and because gall stones are not associated with hypercholesterolaemia, ${ }^{12-15}$ possibly even the reverse. ${ }^{16}$

Lack of dietary fibre has been considered to be a likely contributory factor to gall stones ever since it was shown that feeding wheat bran can lower the cholesterol saturation of bile in the gall bladder. ${ }^{17-19}$ Scragg et al found no difference between patients and controls in their intake of fibre. Does this mean that fibre does not protect against gall stones? Not necessarily. The threshold at which fibre protects may have been higher than the intakes achieved by any of the cases or controls. This threshold effect must always be borne in mind in interpreting negative results in case-control studies. In experimental studies a diet rich in fibre and poor in refined sugars does lower the cholesterol saturation of gall bladder bile, ${ }^{20}$ a beneficial effect which is not explained by the low intake of sugar. ${ }^{7}$ It is certainly not possible to dismiss a protective role for dietary fibre, for which there is considerable evidence from animal studies. ${ }^{21}$

A moderate intake of alcohol seems to protect against gall stones. This has been hinted at by previous epidemiological data, but the Adelaide findings are the first clear cut evidence. By a happy coincidence a mechanism to explain the effect of alcohol has recently been found. ${ }^{22}$ When 12 previously abstemious Bristolians drank half a bottle of wine a day for six weeks their bile-initially supersaturated-became considerably less saturated. The Adelaide data suggest that considerably less than half a bottle of wine may provide protection.

So, to prevent gall stones the overall message seems to be: keep slim, avoid sugar, drink a little alcohol, and, perhaps, keep up a high fibre intake. Osler's acute observation got it very nearly right 100 years ago when he described patients with gall stones as "often stout, and usually very fond of starchy and saccharine food." 23

K W HeAtoN

Reader in Medicine,

Bristol Royal Infirmary,

Bristol BS2 8HW

${ }^{1}$ Bennion LJ, Grundy SM. Effects of obesity and caloric intake on biliary lipid metabolism in man. 7 Clin Invest 1975;56:996-1011.

2 Mabee TM, Meyer P, DenBesten L, Mason EE. The mechanism of increased gallstone formation in obese human subjects. Surgery 1976; $79: 460-8$.

${ }^{3}$ Royal College of General Practitioners' Oral Contraception Study. Oral contraceptives and gallbladder disease. Lancet 1982 ;ii :957-9.

4 Heaton KW. The epidemiology of gallstones and suggested aetiology. Clin Gastroenterol 1973;2:67-83.

5 Bhathena SJ, Avigan J, Schreiner ME. Effect of insulin on sterol and fatty acid synthesis and hydroxymethylglutaryl CoA reductase activity in mammalian cells grown in culture. Proc Natl Acad Sci USA 1974; $71: 2174-8$.

${ }^{6}$ Reiser S, Bohn E, Hallfrisch J, Michaelis OE, Keeney M, Prather ES. Serum insulin and glucose in hyperinsulinemic subjects fed three different levels of sucrose. Am F Clin Nutr 1981;34:2348-58.

7 Werner D, Emmett PM, Heaton KW. The effects of dietary sucrose on factors influencing cholesterol gallstone formation. Gut 1984 ;25:269-74.

8 Sarles H, Crotte C, Gerolami A, Mule A, Domingo N, Hauton J. Influence of cholestyramine, bile salt, and cholesterol feeding on the lipid composition of hepatic bile in man. Scand $\mathcal{f}$ Gastroenterol 1970;5: 603-8.

9 Dam H, Prange I, Jensen MK, Kallehauge HE, Fenger HJ. Studies on human bile. IV. Influence of ingestion of cholesterol in the form of eggs on the composition of bile in healthy subjects. $Z$ Ernaehrungswiss $1971 ; 10: 178-87$.

10 Andersén E, Hellström K. The effect of cholesterol feeding on bile acid kinetics and biliary lipids in normolipidemic and hypertriglyceridemic subjects. F Lipid Res 1979;20:1020-7.

11 DenBesten L, Connor WE, Bell S. The effect of dietary cholesterol on the composition of human bile. Surgery 1973;73:266-73.

12 Sampliner RE, Bennett PH, Comess LJ, Rose FA, Burch TA. Gallbladder disease in Pima Indians. Demonstration of high prevalence and early onset by cholecystography. N Engl f Med 1970;283:1358-64.

13 Friedman GD, Kannel WB, Dawber TR. The epidemiology of gallbladder disease: observations in the Framingham study. $f$ Chronic Dis 1966;19: 273-92.

14 Alhberg J, Angelin B, Einarsson K, Hellström K, Leijd B. Prevalence of gallbladder disease in hyperlipoproteinemia. Dig Dis Sci 1979;24: 459-64.

15 Ahlberg J, Angelin B, Einarsson K, Hellström K, Leijd B. Biliary lipid composition in normo- and hyperlipoproteinemia. Gastroenterology 1980;79:90-4.

16 van der Linden W. Some biological traits in female gallstone-disease patients. Acta Chir Scand 1961;suppl 269:7-94.

17 Pomare EW, Heaton KW, Low-Beer TS, Espiner HJ. The effect of wheat bran upon bile salt metabolism and upon the lipid composition of bile in gallstone patients. American Fournal of Digestive Diseases 1976;21: 521-6.

18 Watts JMcK, Jablonski P, Toouli J. The effect of added bran to the diet on the saturation of bile in people without gallstones. Am $\mathcal{F}$ Surg $1978 ; 135: 321-4$

${ }^{19}$ McDougall RM, Yakymyshyn L, Walker K, Thurston OG. Effect of wheat bran on serum lipoproteins and biliary lipids. Can F Surg 1978; $21: 433-5$.

20 Thornton JR, Emmett PM, Heaton KW. Diet and gall stones: effects of refined and unrefined carbohydrate diets on bile cholesterol saturation and bile acid metabolism. Gut 1983;24:2-6.

${ }^{21}$ Heaton KW. Gallstones and cholecystitis. In: Burkitt DP, Trowell HC, eds. Refined carbohydrate foods and disease. Some implications of dietary fibre. New York: Academic Press, 1975:173-94.

22 Thornton J, Symes C, Heaton K. Moderate alcohol intake reduces bile cholesterol saturation and raises HDL cholesterol. Lancet 1983;ii: 819-22.

${ }^{23}$ Osler W. The principles and practice of medicine. Edinburgh: Pentland, $1892: 432$. 